Running head: Effective model statement use to elicit veracity differences in reporting details 1

Using the Model Statement to Elicit Verbal Differences between Truth tellers and Liars: The Benefit of Examining Core and Peripheral Details

\author{
Sharon Leal \\ Aldert Vrij \\ Haneen Deeb \\ Louise Jupe \\ Department of Psychology, University of Portsmouth
}

\begin{abstract}
Author notes
Correspondence concerning this article should be addressed to Sharon Leal, Department of Psychology, University of Portsmouth, King Henry Building, King Henry 1 Street, PO1 2DY, Hants, United Kingdom. Email: sharon.leal@ port.ac.uk
\end{abstract}




\begin{abstract}
Research has shown that a model statement elicits more information during an interview and that truth tellers and liars report a similar amount of extra information. We hypothesised that Veracity differences would arise if the total amount of information would be split up into core details and peripheral details. A total of 119 truth tellers and liars reported a stand-out event that they had experienced in the last two years. Truth tellers had actually experienced the event and liars made up a story. Half of the participants were given a model statement during the interview. After exposure to a model statement, truth tellers and liars reported a similar amount of extra core information, but liars reported significantly more peripheral information. The variable 'details' becomes an indicator of deceit in a model statement interview protocol as long as a distinction is made between core and peripheral details.
\end{abstract}


General audience summary

Research has shown that a model statement, an example of a detailed report about an event unrelated to the topic of investigation, elicits more information during an interview and that truth tellers and liars report a similar amount of extra information. Interviewees typically underestimate how much information is required from them in an interview and the model raises the expectations amongst both truth tellers and liars about how much information they should provide. We tested the hypothesis that differences between truth tellers and liars would arise if the total amount of information was split into two categories: core details and peripheral details. A total of 119 truth tellers and liars reported a stand-out event that they had experienced in the last two years. Truth tellers had actually experienced the event and liars made up a story. Half of the participants were given a model statement during the interview. After exposure to a model statement, truth tellers and liars reported a similar amount of extra core information, but liars reported significantly more peripheral information. The variable 'details' becomes an indicator of deceit in a model statement interview protocol as long as a distinction is made between core and peripheral details. 


\section{Using the Model Statement to Elicit Verbal Differences between Truth tellers and Liars: The Benefit of Examining Core and Peripheral Details}

The verbal cues to deceit that liars show spontaneously are weak (DePaulo et al., 2003). Researchers have therefore started to examine whether such cues can be elicited or enhanced through specific interview protocols (Vrij, Fisher, \& Blank, 2017; Vrij \& Granhag, 2012). One such protocol is the model statement technique. A model statement is an example of a detailed report about an event unrelated to the topic of investigation, usually presented in an audio-format at some time during an interview (Leal, Vrij, Warmelink, Vernham, \& Fisher, 2015). Interviewees typically underestimate how much information is required from them (Vrij, Hope, \& Fisher, 2014). The theoretical underpinning of the detailed model statement is that it works as a social comparison (Cialdini, 2007; Festinger, 1954) raising the expectations amongst both truth tellers and liars about how much information they should provide (Ewens et al., 2016). As a result, both truth tellers and liars provide more details after being exposed to a model statement (Ewens et al., 2016; Leal et al., 2015). A model statement may work better than an instruction to 'report all details' because a model statement is an example, and examples are easier to follow than instructions.

The model statement facilitated the elicitation of information in all eight deception studies published to date that we are aware of (Bogaard, Meijer, \& Vrij, 2014; Ewens et al., 2016; Harvey, Vrij, Leal, Lafferty, \& Nahari, 2017; Kleinberg, van der Toolen, Vrij, Arntz, \& Verschuere, 2018; Leal et al., 2015; Porter et al., 2017; Vrij, Leal, Jupe, \& Harvey, 2018; Vrij et al., 2017). However, the technique has generally been unsuccessful at enhancing the differences between truth tellers and liars regarding the amount of details they provide, as both groups tend to add a similar amount of detail when exposed to a model statement (but see Porter et al. [2017] for an exception). A possible explanation for this is that measuring total details alone does not take into account the differential strategies truth tellers and liars 
employ. Differential strategies are taken into account when a distinction is made between core and peripheral details, as we examined in the current experiment.

Heuer and Reisberg (1990) defined core details as details that, if changed, can result in changes in the basic and most important part of the story; details that have no such impact are considered peripheral. This definition, although helpful, still requires a subjective judgment about the basic meaning to identify central and peripheral content, something that cannot be avoided when defining core and peripheral details (Yegiyan, \& Lang, 2010). In the present study, we differentiated core events from peripheral events. If someone discusses attending an Adele concert, the core event is the actual concert, therefore all details that are about the actual concert are considered core details. Peripheral events concern the drinks in the pub before and after the concert and all details about these events are considered peripheral details.

Both truth tellers and liars realise that providing a lot of information makes a sincere impression on observers (Bell \& Loftus, 1989; Johnson, Foley, Suengas, \& Raye, 1988). Thus, a model statement will motivate both truth tellers and liars to provide more information. Truth tellers, who have actually experienced an event, will be able to provide more core and peripheral information, by employing a 'tell it all strategy' (Hartwig, Granhag, \& Strömwall, 2007). For liars, providing more core information is difficult and risky. It is difficult because they have not actually experienced the event and thus have to make up information; and risky because the additional information may provide leads to investigators that the information they have given is untrue. Thus liars may avoid providing more core details, in an attempt to minimise the risk of presenting incriminating information (Granhag \& Hartwig, 2008; Nahari, Vrij, \& Fisher, 2014), but may compensate for this by providing a lot of peripheral detail to satisfy the increased expectations created by the model statement regarding how much information they should provide. 
In the current study truth tellers and liars gave an initial free recall which was then followed — or not followed — by a model statement. Hereafter the interviewees gave a second free recall. This second free recall was followed by the request to tell the story in reverse chronological order. Reverse order recall stimulates a truth teller to think about the event again but now from a different perspective. That often leads to additional information (Fisher \& Geiselman, 1992). It may lead to even more additional information if truth tellers were initially exposed to a model statement. For two reasons it is unlikely that liars will report as much additional information as truth tellers. First, additional information results in less consistency (Vredeveldt, van Koppen, \& Granhag, 2014), and liars often believe that it is important to be consistent in order to make a credible impression (Deeb et al., 2018; Strömwall, Granhag, \& Hartwig, 2004). Second, a reverse order recall is mentally taxing, particularly for liars, whose cognitive resources have already been partially depleted by the cognitively demanding task of lying (Vrij et al., 2008). Experiencing substantial cognitive load while reporting in reverse order, may result in providing fewer details, regardless of the type of detail (core or peripheral).

\section{Hypotheses}

In the second recall, more core and peripheral details will be reported in the model statement present than in the model statement absent condition (Hypothesis 1). Truth tellers will report more new core details than liars in the second recall, particularly in the model statement present condition (Hypothesis 2). Liars will report more new peripheral details than truth tellers in the second recall, particularly in the model statement present condition (Hypothesis 3). Liars will report fewer new core and peripheral details than truth tellers in the reverse order recall, particularly in the model statement present condition (Hypothesis 4).

\section{Method}

\section{Participants and Design}


A total of 120 participants were recruited, through the departmental participant pool and announcements posted in university buildings. Participants were invited to take part in a study that examined how good individuals are at telling the truth or lying about memorable events. Participants received a reward of either one course credit or $£ 10$ for taking part in the research, and their names were entered in a draw to win a prize of $£ 50, £ 75$, or $£ 150$. The sample included 93 females and 27 males, and their average age was 23.76 years $(S D=9.56)$.

A 2 (Veracity: truth teller vs liar) $\times 2$ (Model Statement: absent vs present) betweensubjects design was used. Participants were randomly allocated to the Veracity and Model Statement conditions with 30 participants in each cell. The dependent variables were initial total details, initial core details, initial peripheral details, new core details in second recall, new peripheral details in second recall, total new details in second recall, new core details in reverse order recall, new peripheral details in reverse order recall, and total new details in reverse order recall.

\section{Procedure}

Initial instructions. On arrival at the Psychology Department, all participants signed a consent form. Truth tellers were asked to think of a memorable event that happened to them in the past two years. The event should have been an out of the ordinary event that they (or others) do not experience daily. Truth tellers were given examples of such events (e.g., seeing a famous person when they were out for dinner, or going on a pheasant shoot). Liars and truth tellers were matched for memorable events. That is, liars were asked to lie about an event chosen by a truth teller and to pretend they have experienced that event. Matched liars and truth tellers were allocated to the same Model Statement condition.

All participants were informed that they will be interviewed about the event and they will need to convince the interviewer that they are honest. To motivate participants, they were told that if they are convincing, their names will be entered in a draw to win $£ 50, £ 75$, or $£ 150$. 
However, if they are not convincing, they will be asked to write a statement about the event and their names will not be entered in the draw. In reality, all participants were entered in the draw and nobody was asked to write a statement. Participants then honestly completed a preinterview questionnaire that asked about their background characteristics and their motivation to convince the interviewer $(1=$ not at all to $7=$ completely $)$.

Interviews. One of three interviewers, blind to the participants' Veracity condition and to the study hypotheses, interviewed participants. In the first interview, all participants were asked to give an initial detailed free recall of the event. "Hello, I understand from my colleague that on <month and year > you <event >. Could you please tell me in as much detail as possible everything about that event?" After this initial recall, in all conditions the interviewer left the room and returned after about fifteen seconds. The interviewer then introduced the request for the second recall in the model absent condition as follows: "Sorry but I am going to have to ask you again. Please tell me in as much detail as possible exactly what happened on <month and year > when you < event >?" In the model statement present condition, the request for the second recall was introduced as follows: "Please tell me in as much detail as possible exactly what happened on <month and year > when you <event $>$ but this time before doing so I would like to play you a model statement to give you an idea of exactly how much detail I would like you to include in your response. OK?"

An audiotaped model statement was then played. It was 1.30 minutes long detailed account of someone attending a Formula 2 motor racing event (Leal et al., 2015). The account was a spontaneous, unscripted recall of an event truly experienced by the person. After the model statement, the interviewer continued as follows: "OK so remembering the amount of detail in the model statement, could you please tell me once more what happened on <month and year > when you <event>?" 
After the interviewees provided the second recall, the reverse order request was introduced as follows (in both the model statement absent and present conditions): "Thank you that was helpful, however, we know from research that asking individuals to recall their statement in reverse order helps with their memory of the event. Therefore, I would like you to recall the event, in reverse order, starting from when <event $>$ ended and talk back to when <event $>$ started." After completing the reverse order recall, participants were asked to rate on a percentage scale $(0 \%-100 \%)$ the extent to which they were truthful in their recalls. Lastly, they were fully debriefed, rewarded, and thanked.

\section{Coding}

All interviews were audiotaped, transcribed and coded for details. Every noun, verb, adjective, and adverb was considered a single detail, but other details such as conjunctions, prepositions, and pronouns were not counted because they are not precise and thus not informative. For example, the sentence "I went to Heathrow airport, which is an international airport, to get my friend" included six details (went, Heathrow, international, airport, get, friend). A distinction was made between core and peripheral details. An example of core details is that of a participant who talked about taking part in his graduation ceremony: "The chancellor was introduced, and then he started giving out the certificates". This statement described information that concerned the target event and included six core details (chancellor, introduced, then, started, giving, certificates). The same participant provided information that was peripheral or irrelevant to the target event when saying: "Two of my friends were staying in the hotel, so we went for breakfast". This statement included six peripheral details (two, friends, staying, hotel, went, breakfast).

Details that were repeated in a single recall were coded only once unless they occurred in different contexts. An example of two different contexts is that provided by a participant who took a taxi to the airport and then took a taxi from the destination airport to 
the hotel. Here, 'taxi' was coded twice, because the context of going to the airport differed from that of leaving the destination airport, and transportation means might have differed across the two contexts. In other instances, the participant could have taken a taxi to the airport but a train from the airport destination. Hence, the participant provided additional and useful information which merited coding the same detail twice. In the second and third recalls, new core and peripheral details were marked. Details mentioned in the second recall but not in the initial recall, and details mentioned only in the third reverse order recall were marked as new details.

Two coders, blind to veracity and model statement conditions and experienced in coding deception data, coded the transcripts. They started by coding interviews from four participants. Disagreements between them were discussed and resolved. One coder coded all the transcripts, and the second coder coded 20 transcripts. Inter-rater reliability analyses revealed that the Intra-Class Correlation coefficients (ICC, single measures scores) were .84 for core details, .64 for peripheral details, and .81 for new details. Although a .64 score is not high, inter-rater coefficients in the .60 range, or even lower, occur more often in verbal cues to deception research (Vrij, 2005; Vrij et al., 2017; 2018).

\section{Results}

One participant had z-scores that were higher than 3.29 on core details in the initial recall, and new core and peripheral details in the second recall, and was thus considered an outlier (Field, 2009). None of the other participants had such high z-scores on these variables, so data from this participant was deleted. Hence, the final sample included 119 participants with 59 participants in the truth-teller and Model Statement conditions and 60 participants in the liar and No Model Statement conditions.

\section{Motivation and Truthfulness}


Truth tellers $(M=6.46, S D=.73,95 \%$ CI $[6.23,6.69])$ reported to be more motivated than liars $(M=5.98, S D=1.02,95 \%$ CI $[5.76,6.21])$ to convince the interviewer of their truthfulness, $F(1,117)=8.55, p=.004, d=.54,95 \%$ CI $[.17, .90]$. However, the average mean score shows that also liars reported to be very motivated.

Truth tellers reported to have been overwhelmingly truthful $(M=96.78, S D=13.44)$ whereas liars were not $(M=15.17, S D=22.06)$. This difference was of course significant, $F(1,117)=591.96, p<.001, d=4.46,95 \%$ CI $[3.73,5.06]$. That liars were to some extent truthful $(15.17 \%)$ is not surprising and fits well with the notion that liars, where possible, try to embed their lies in truthful stories (Leins, Fisher, \& Ross, 2013).

\section{Preliminary Analyses}

Three 2 (Veracity: truth vs lie) X 2 (Model Statement: present vs absent) ANOVAs were carried out with total details, core details and peripheral details in the initial recall as dependent variables. We included the model statement as factor in this analysis, despite this factor being only introduced after the initial recall, to rule out any pre-existing differences in Veracity effects between Model Statement conditions prior to the model statement manipulation. Truth tellers reported more details than liars in the initial recall, see Table 1. This is a typical finding in deception research (Amado, Arce, \& Fariña, 2015; Vrij, 2008). The results further revealed that truth tellers reported more core details than liars, whereas no significant difference emerged for peripheral details, see Table 1. The three Model Statement main effects were not significant, all $F{ }^{\prime} s<1.74$, all $p$ 's $>.190$, neither were the three Veracity X Model Statement interaction effects, all $F$ 's $<0.65$, all $p$ ' $s>.421$. This is not surprising because the model statement manipulation was introduced after the initial free recall.

\section{Hypotheses Testing}


A 2 (Veracity: truth vs lie) X 2 (Model Statement: present vs absent) MANOVA was carried out with four dependent variables: the new core and peripheral details in the second recall and the new core and peripheral details in the reverse order recall. At a multivariate level the analysis revealed significant main effects for Veracity, $F(4,112)=4.47, p=.002$, $\eta_{\mathrm{p}}{ }^{2}=.14$ and Model Statement, $F(4,112)=10.91, p<.001, \eta_{\mathrm{p}}{ }^{2}=.28$. The Veracity X Model Statement interaction effect was not significant, $F(4,112)=2.28, p=.065, \eta_{\mathrm{p}}{ }^{2}=.08$.

Insert Tables 1 and 2 about here

At a univariate level, two significant Veracity main effects occurred. Truth tellers provided more new core details in the second recall and in the reverse order recall than liars, see Table 1. At a univariate level, also two Model Statement effects occurred. In the Model Statement present condition, more new core details and more new peripheral details were reported in the second recall than in the Model Statement absent condition, see Table 2. This supports Hypothesis 1.

We predicted significant Veracity X Model Statement interaction effects for all four dependent variables. At a univariate level, for the second recall, a significant interaction effect emerged for new peripheral details, $F(1,115)=4.82, p=.030, \eta_{\mathrm{p}}{ }^{2}=.04$, but the interaction effect for new core details was not significant, $F(1,115)=2.61, p=.109, \eta_{\mathrm{p}}{ }^{2}=$ .02. The interaction effects for reverse order recall were not significant for new core details, $F(1,115)=1.18, p=.280, \eta_{\mathrm{p}}^{2}=.01$, or new peripheral details, $F(1,115)=0.12, p=.735, \eta_{\mathrm{p}}{ }^{2}$ $=.001$. Follow up tests were carried out for the model statement absent and present conditions separately. We not only examined Veracity effects for new peripheral details in the second recall (the significant interaction effect), but also for the core effects in the second and reverse order recalls. Since we obtained main Veracity effects for these two latter variables, we wanted to examine whether the two model statement conditions contributed to this main effect in an equal manner. In addition, relying on the significance of an interaction 
effect is relying on a $p$-value. A $p$-value provides information about the statistical relevance but not about the practical importance of an effect (Du Prel, Hommel, Röhrig, \& Blettner, 2009; Fritz, Morris, \& Richler, 2012). In this article, we are interested in the practical relevance of the Veracity effect and $d$-values are indicators of practical relevance (Fritz et al., 2012). Comparing $d$-values between the two model statement conditions - what we did in the further analyses - is thus important for this article. See Deeb et al. (2017), Nahari and BenShakhar (2011), and Vrij et al. (2017) for a similar approach. The results are presented in Table 3.

\section{Insert Table 3 about here}

In both the model statement absent and model statement present conditions of the second recall, truth tellers reported more new core details than liars. Also the effect sizes in both conditions were very similar ( $d$ 's are .71 vs .70), as shown in Table 3 . This means that Hypothesis 2 has been rejected. Also in the second recall, liars reported more new peripheral details than truth tellers, but only in the model statement present condition. The effect size was also larger in the model statement present condition $(d=.57)$ than in the model statement absent condition $(d=.15)$. This supports Hypothesis 3. In the reverse order recall, truth tellers provided more new core details than liars, but only in the model statement present condition. However, effect sizes were comparable in the model statement present $(d=.68)$ and model statement absent condition $(d=.45)$. This rejects Hypothesis 4 .

We finally carried out two 2 (Veracity: truth vs lie) X 2 (Model Statement: present vs absent) ANOVAs with total new details (new core details and new peripheral details combined) in the second recall and reverse order recall as dependent variables. Truth tellers reported more new details in both the second and reverse order recall, see Table 1. In addition, in the second recall, the interviewees reported more details in the model statement present than in the model statement absent condition, see Table 2. The interaction effects for 
the new total details in the second recall, $F(1,115)=0.54, p=.466, \eta_{\mathrm{p}}{ }^{2}=.005$, and reverse order recall, $F(1,115)=1.16, p=.284, \eta_{\mathrm{p}}^{2}=.010$, were not significant, but, for the reason described above, since we obtained significant Veracity main effects for these variables we examined the Veracity effects for the two model statement conditions separately, see Table 3.

Truth tellers reported more new details than liars in the second recall, but only in the model statement absent condition. However, the effect sizes between the model statement absent $(d=.68)$ and model statement present conditions $(d=.47)$ did not differ much. Truth tellers reported more new details than liars in the reverse order recall, but only in the model statement present condition. Again, the effect sizes between the model statement absent $(d=$ $.30)$ and model statement present conditions $(d=.56)$ did not differ much. This means that truth tellers and liars responded similarly in terms of providing new details after being exposed to a model statement, supporting previous model statement research when total details were taken into account.

\section{Discussion}

The present study replicated the 'total details' findings of most previous deception studies examining the model statement technique: i) Exposure to a model statement increased the amount of new details interviewees provided; ii) since truth tellers and liars provided a similar amount of new details, total details did not facilitate discrimination between them.

A different pattern of results emerged when the variable 'new details' was split into two different variables: new core details and new peripheral details. The difference was found regarding peripheral details: Liars and truth tellers reported a similar amount of new peripheral details in the model statement absent condition but liars reported considerably more peripheral details than truth tellers in the model statement present condition. We thus can conclude that the model statement elicited one cue to deceit: new peripheral details. From a practical point of view, the findings thus suggest that investigators should listen to the 
amount of new peripheral details interviewees report after exposure to a model statement. Those who add many new peripheral details -and thus seem to beat around the bush- may be lying.

The practical value of using the model statement is further enhanced by its simplicity to use: All that is required is to ask an interviewee to listen to a detailed audiotaped statement about a topic unrelated to the topic under investigation. Finally, by examining new details an interviewee provides, we are introducing a within-subjects measurement, comparing two statements made by the same interviewee. It is not the ideal within-subjects comparison everyone adds peripheral details- but it is still better than a single statement analysis (Vrij, 2016). If just amount of peripheral detail is considered -the only method of analysis in a single statement analysis- the problem arises that this will not only be affected by veracity but also by other factors including eloquence. Additional factors play a lesser role in withinsubjects comparisons, because it is no longer relevant how many peripheral details are influenced by being eloquent, but it becomes relevant how many additional peripheral details are included (more likely to be influenced by veracity).

The finding that examining new peripheral details yielded better results in terms of distinguishing truth tellers from liars than examining total new details is not surprising, because the former takes into account the strategies liars use, whereas the latter does not. These differential strategies are triggered particularly when a model statement is used. In that condition, liars are encouraged to provide more information, which in their case is most likely peripheral information. Taking into account different strategies employed by liars in interviews to detect deception has proven to be beneficial before, see the Strategic Use of Evidence (Granhag \& Hartwig, 2015; Hartwig, Granhag, \& Luke, 2014) and the Verifiability Approach (Nahari, 2018b; Nahari, Vrij, \& Fisher, 2014). 
Core details did not become an indicator of deceit after introduction of the model statement. Unlike peripheral details, for core details a Veracity effect already existed in the initial interview, thus prior to introducing a model statement, which creates less opportunity for more enhanced veracity effects for core differences to arise in the further parts of the interview. Additionally, the number of core details provided by liars initially (8.10) was low relative to the number of core details provided by truth tellers initially (19.19). Therefore, liars had more opportunity to report additional details than for truth tellers; also what truth tellers can add is constrained by what they can remember, whereas liars do not have such memory constraints (Nahari, 2018a).

Someone could argue that results would have represented better practical value if the model statement elicited differences between truth tellers and liars in presenting core details, as such details matter most in an interview. Although true, the present findings regarding core details still may facilitate lie detection. Listening to a model statement may make liars aware that they also need to add details about the core event to appear credible. The additional details liars provide about the core event, may subsequently be checked by investigators and indicate deceit.

Truth tellers reported more additional core details in the reverse order recall than liars, and this replicates previous deception reverse order recall research (Vrij, Leal, Mann, \& Fisher, 2012). The reverse order technique was initially developed for use with cooperative witnesses (Fisher \& Geiselman, 1992) but could be a useful tool to detect deception when applied appropriately. We discourage using the reverse order technique as a method to distinguish between cognitive load experienced by truth tellers and liars because both groups will experience increased cognitive load in a reverse order recall (Vrij \& Fisher, 2016). Instead, we recommend that investigators pay attention to the amount of new information 
provided in a reverse order recall, with truth tellers likely to report more additional information than liars.

The model statement had no effect on the amount of detail elicited from the reverse order question. The absence of a model statement effect in the current study could have been caused by at least four factors. First, a lack of motivation. By the time the reverse order question was asked, truth tellers and liars had already reported their stories twice. Asking them to report it for a third time may have been too much. We found some indirect evidence for this assumption: The reverse order recalls were shorter than the initial and second recalls ${ }^{1}$. If the absence of an effect is caused by lack of motivation, real life interviews in which interviewees are probably more motivated may yield different results. A second explanation is that interviewees were saturated after two recalls and simply could not report much new information. In that scenario, real life interviews may produce similar findings as reported in the current article. A third explanation is that the effect of a model statement does not last long in an interview. In that respect, a better result may have been obtained if the interviewee was reminded again of the model statement when the reverse order question was asked (e.g., "Taking into account the amount of details you heard in the model statement, could you please .....'?). Finally, a reverse order recall is mentally taxing (Vrij et al., 2008), and perhaps too difficult to encourage long responses.

In the model statement present condition, interviewees reported more new information than in the model statement absent condition. The ability of a model statement to elicit additional information has been well documented and is not the main finding of the current experiment. However, it is worth mentioning this effect because eliciting information is an important aim of an investigative interview (Vrij, Hope, \& Fisher, 2014). A model statement can thus achieve two goals simultaneously: It elicits information and facilitates lie detection. 


\section{Acknowledgement}

This work was funded by the Centre for Research and Evidence on Security Threats (ESRC Award: ES/N009614/1)

\section{Author Contributions}

The first and second author designed the experiment and wrote the article together. The second author carried out the statistical analyses. The third and fourth authors collected the data. The third author commented on a draft version of the article. 


\section{References}

Amado, B. G., Arce, R., Fariña, F. (2015). Undeutsch hypothesis and Criteria Based Content Analysis: A meta-analytic review. The European Journal of Psychology Applied to Legal Context, 7, 3-12. Doi:10.1016/j.ejpal.2014.11.002

Bell, B. E., \& Loftus, E. F. (1989). Trivial persuasion in the courtroom: The power of (a few) minor details. Journal of Personality and Social Psychology, 56, 669-679. Doi:10.1037//0022-3514.56.5.669

Bogaard, G., Meijer, E. H., \& Vrij, A. (2014). Using an example statement increases information but does not increase accuracy of CBCA, RM, and SCAN. Journal of Investigative Psychology and Offender Profiling, 11, 151-163. Doi:10.1002/jip.1409

Cialdini, R. B. (2007). Influence: The psychology of persuasion. New York, NY: William Morrow and Company.

Deeb, H., Vrij, A., Hope, L., Mann, S., Granhag, P. A., \& Lancaster, G. L. J. (2017). Suspects' consistency in statements concerning two events when different question formats are used. Journal of Investigative Psychology and Offender Profiling, 14, 7487. Doi:10.1002/jip.1464

Deeb, H., Vrij, A., Hope, L., Mann, S., Granhag, P. A., \& Strömwall, L. A. (2018). Police officers' perceptions of statement inconsistency. Criminal Justice and Behavior. Advance online publication. Doi:10.1177/0093854818758808

DePaulo, B. M., Lindsay, J. L., Malone, B. E., Muhlenbruck, L., Charlton, K., \& Cooper, H. (2003). Cues to deception. Psychological Bulletin, 129, 74-118. Doi:10.1037/00332909.129.1.74

Du Prel, J-B., Hommel, G., Röhrig, B., \& Blettner, M. (2009). Confidence interval or pvalue? Deutzches Arzteblatt International, 106, 335-339.

Doi:10.3238/arztebl.2009.0335. 
Ewens, S., Vrij, A., Leal, S., Mann, S., Jo, E., Shaboltas, A., Ivanova, M., Granskaya, J., \& Houston, K. (2016). Using the model statement to elicit information and cues to deceit from native speakers, non-native speakers and those talking through an interpreter. Applied Cognitive Psychology, 30, 854-862. Doi:10.1002/acp.3270

Festinger, L. (1954). A theory of social comparison processes. Human Relations, 7, 117-140. Doi:10.1177/001872675400700202

Field, A. (2009). Discovering statistics using SPSS (third edition). Los Angeles, CA: Sage.

Fisher, R. P., \& Geiselman, R. E. (1992). Memory enhancing techniques for investigative interviewing: The Cognitive Interview. Springfield, Illinois: Charles C. Thomas.

Fritz, C. O., Morris, P. E., \& Richler, J. J. (2012). Effect size estimates: Current use, calculations and interpretation. Journal of Experimental Psychology: General, 141, 218. Doi:10.1037/a0024338

Granhag, P.A. \& Hartwig, M. (2008). A new theoretical perspective on deception detection: On the psychology of instrumental mind-reading. Psychology, Crime \& Law, 14, 189-200. Doi: 10.1080/10683160701645181

Granhag, P. A., \& Hartwig, M. (2015). The Strategic Use of Evidence (SUE) technique: A conceptual overview. In P. A. Granhag, A. Vrij, \& B. Verschuere (Eds.), Deception detection: Current challenges and new approaches (pp. 231-251). Chichester, West Sussex: Wiley.

Hartwig, M., Granhag, P. A., \& Luke, T. (2014). Strategic use of evidence during investigative interviews: The state of the science. In Raskin, D. C., Honts, C. R., Kircher, J. C. (Eds.), Credibility assessment: Scientific research and applications (pp. 1-36). Kidlington, Oxford: Academic Press. 
Hartwig, M., Granhag, P. A., \& Strömwall, L. (2007). Guilty and innocent suspects' strategies during police interrogations. Psychology, Crime, \& Law, 13, 213-227. Doi: $10.1080 / 10683160600750264$

Harvey, A., Vrij, A., Leal, S., Lafferty, M., \& Nahari, G. (2017). Insurance based lie detection: Enhancing the Verifiability Approach with a model statement component. Acta Psychologica, 174, 1-8. Doi:10.1016/j.actpsy.2017.01.001.

Heuer, F. \& Reisberg, D. (1990). Vivid memories of emotional events: The accuracy of remembered minutiae. Memory \& Cognition, 18: 496-506. Doi: 10.3758/BF03198482.

Johnson, M. K., Foley, M. A., Suengas, A. G., \& Raye, C. L. (1988). Phenomenal characteristics of memories for perceived and imagined autobiographical events. Journal of Experimental Psychology: General, 117, 371-376. Doi:10.1037//0096-3445.117.4.371

Kleinberg, B. A. R., van der Toolen, Y., Vrij, A., Arntz, A. R., \& Verschuere, B. J. (2018). Automated verbal credibility assessment of intentions: The model statement technique and predictive modelling. Applied Cognitive Psychology.

Leal, S., Vrij, A., Warmelink, L., Vernham, Z., \& Fisher, R. (2015). You cannot hide your telephone lies: Providing a model statement as an aid to detect deception in insurance telephone calls. Legal and Criminological Psychology, 20, 129-146.

Doi:10.1111/lcrp.12017

Leins, D., Fisher, R. P., \& Ross, S. J. (2013). Exploring liars' strategies for creating deceptive reports. Legal and Criminological Psychology, 18, 141-151. Doi:10.1111/j.20448333.2011.02041.x

Nahari, G. (2018a). Reality Monitoring in the forensic context: Digging deeper into the speech of liars. Journal of Applied Research in Memory and Cognition. Doi: 10.1016/j.jarmac.2018.04.003 
Nahari, G. (2018b). The applicability of the Verifiability Approach to the real world. In P. Rosenfeld (Ed.). Detecting concealed information and deception: Verbal, behavioral, and biological methods (pp. 329-350). San Diego, CA: Academic Press.

Nahari, G., \& Ben-Shakhar, G. (2011). Psychophysiological and behavioural measures for detecting concealed information: The role of memory for crime details. Psychophysiology, 48, 733-744. Doi:10.1111/j.1469-8986.2010.01148.x

Nahari, G., Vrij, A., \& Fisher, R. P. (2014). Exploiting liars' verbal strategies by examining the verifiability of details. Legal and Criminological Psychology, 19, 227-239. Doi:10.1111/j.2044-8333.2012.02069.x

Porter, C., Vrij, A., Leal, S., Vernham, Z., Salvanelli, G., McIntyre, N. (2017). Using specific Model Statements to elicit information and cues to deceit in information-gathering Interviews. Journal of Applied Research in Memory and Cognition. Advance online publication. Doi:10.1016/j.jarmac.2017.10.003

Strömwall, L. A., Granhag, P. A., \& Hartwig, M. (2004). Practitioners' beliefs about deception. In P. A. Granhag \& L. A. Strömwall (Eds.), The detection of deception in forensic contexts (pp. 229-250). Cambridge, England: Cambridge University Press.

Vredeveldt, A., van Koppen, P. J., Granhag, P. A. (2014). The inconsistent suspect: A systematic review of different types of consistency in truth tellers and liars. In R. Bull (Ed.), Investigative interviewing (pp. 183-207). New York, NY: Springer Science+Business Media. Doi:10.1007/978-1-4614-9642-7_10

Vrij, A. (2008). Detecting lies and deceit: Pitfalls and opportunities. Chichester, West Sussex: John Wiley \& Sons. 
Vrij, A. (2016). Baselining as a lie detection method. Applied Cognitive Psychology, 30, 1112-1119. Doi: 10.1002/acp.3288

Vrij, A., \& Fisher, R. P. (2016). Which lie detection tools are ready for use in the criminal justice system? Journal of Applied Research in Memory and Cognition, 5, 302-307. Doi:10.1016/j.jarmac.2016.06.014

Vrij, A., Fisher, R., Blank, H. (2017). A cognitive approach to lie detection: A meta-analysis. Legal and Criminological Psychology, 22, 1-21. Doi:10.1111/lcrp.12088

Vrij, A., \& Granhag, P. A. (2012). Eliciting cues to deception and truth: What matters are the questions asked. Journal of Applied Research in Memory and Cognition, 1, 110-117. Doi:10.1016/j.jarmac.2012.02.004

Vrij, A., Hope, L., \& Fisher, R. P. (2014). Eliciting reliable information in investigative interviews. Policy Insights from Behavioral and Brain Sciences, 1, 129-136. Doi: $10.1177 / 2372732214548592$

Vrij, A., Leal, S., Fisher, R. P., Mann, S., Dalton, G. Jo, E., Shaboltas, A., Khaleeva, M., Granskaya, J., \& Houston, K. (2018). Sketching as a technique to elicit information and cues to deceit in interpreter-based interviews. Journal of Applied Research in Memory and Cognition. Doi: 10.1016/j.jrarmac.2017.11.001

Vrij, A., Leal, S., Jupe, L., \& Harvey, A. (2018). Within-subjects verbal lie detection measures: A comparison between total detail and proportion of complications. Legal and Criminological Psychology. Doi:10.1111/lcrp.12126

Vrij, A., Leal, S., Mann, S., Dalton, G. Jo, E., Shaboltas, A., Khaleeva, M., Granskaya, J., \& Houston, K. (2017). Using the Model Statement to elicit information and cues to deceit in interpreter-based interviews. Acta Psychologica, 177, 44-53.

Doi:10.1016/j.actpsy.2017.04.011 
Vrij, A., Leal, S., Mann, S., \& Fisher, R. (2012). Imposing cognitive load to elicit cues to deceit: Inducing the reverse order technique naturally. Psychology, Crime, \& Law, 18, 579-594. Doi:10.1080/1068316X2010.515987

Vrij, A., Mann, S., Fisher, R., Leal, S., Milne, B., \& Bull, R. (2008). Increasing cognitive load to facilitate lie detection: The benefit of recalling an event in reverse order. Law and Human Behavior, 32, 253-265. Doi:10.1007/s10979-007-9103-y.

Yegiyan, N. S. \& Lang, A. (2010). Processing central and peripheral detail: How content arousal and emotional tone influence encoding. Media Psychology, 13, 77-99. Doi: $10.1080 / 15213260903563014$ 
Table 1

Total (New) Details, (New) Core Details, and (New) Peripheral Details in the Three Recalls as a Function of Veracity

\begin{tabular}{|c|c|c|c|c|c|c|c|c|}
\hline & \multicolumn{2}{|c|}{ Truth } & \multicolumn{2}{|c|}{ Lie } & \multirow{2}{*}{$\boldsymbol{F}$} & \multirow{2}{*}{$p$} & \multicolumn{2}{|c|}{ Cohen's $d$} \\
\hline & $M(S D)$ & $95 \% \mathrm{CI}$ & $M(S D)$ & $95 \% \mathrm{CI}$ & & & $d$ & $95 \% \mathrm{CI}$ \\
\hline Total number of details in initial recall & $78.78(44.22)$ & $69.41,87.73$ & $52.63(23.59)$ & $43.64,61.80$ & 15.76 & $<.001$ & 0.74 & $0.36,1.10$ \\
\hline Peripheral details in initial recall & $12.93(15.62)$ & $08.76,17.03$ & $17.60(16.43)$ & $13.61,21.80$ & 02.68 & .104 & 0.29 & $-0.07,0.65$ \\
\hline New core details in second recall & $39.69(46.84)$ & $32.43,49.15$ & $20.50(22.30)$ & $11.18,28.38$ & 12.13 & .001 & 0.52 & $0.15,0.88$ \\
\hline New core details in reverse order recall & $11.53(14.83)$ & $08.60,14.63$ & $04.92(07.25)$ & $01.95,07.92$ & 09.73 & .002 & 0.57 & $0.19,0.93$ \\
\hline New peripheral details in reverse order recall & $03.86(12.00)$ & $01.39,06.42$ & $03.97(06.62)$ & $01.47,06.46$ & 00.00 & .972 & 0.18 & $-0.35,0.37$ \\
\hline Total new details in second recall & $46.24(49.37)$ & $38.35,56.43$ & $30.88(28.80)$ & $21.33,39.25$ & 07.08 & .009 & 0.38 & $0.01,0.74$ \\
\hline Total new details in reverse order recall & $15.39(18.75)$ & $09.36,17.02$ & $09.38(10.71)$ & $05.10,12.70$ & 05.90 & .017 & 0.39 & $0.03,0.75$ \\
\hline
\end{tabular}


Table 2

Total New Details, New Core Details, and New Peripheral Details in the Second and Reverse Order Recalls as a Function of Model Statement

\begin{tabular}{|c|c|c|c|c|c|c|c|c|}
\hline & \multicolumn{2}{|c|}{ Model statement absent } & \multicolumn{2}{|c|}{ Model statement present } & \multirow{2}{*}{$\boldsymbol{F}$} & \multirow{2}{*}{$p$} & \multicolumn{2}{|c|}{ Cohen's $d$} \\
\hline & $M(S D)$ & $95 \% \mathrm{CI}$ & $M(S D)$ & $95 \% \mathrm{CI}$ & & & $d$ & $95 \% \mathrm{CI}$ \\
\hline New core details in second recall & $13.83(16.52)$ & $05.37,21.93$ & $46.47(45.44)$ & $38.89,55.61$ & 31.97 & $<.001$ & 0.96 & $0.56,1.32$ \\
\hline New core details in reverse order recall & $07.77(09.92)$ & $04.71,10.68$ & $08.63(13.97)$ & $05.84,11.87$ & 00.30 & .588 & 0.07 & $-0.29,0.43$ \\
\hline New peripheral details in reverse order recall & $03.52(06.93)$ & $01.04,06.02$ & $04.32(11.81)$ & $01.82,06.85$ & 00.20 & .652 & 0.18 & $-0.28,0.44$ \\
\hline
\end{tabular}


Table 3

Total New Details, New Core Details, and New Peripheral Details as a Function of Veracity and Model Statement

\begin{tabular}{|c|c|c|c|c|c|c|c|c|}
\hline & \multicolumn{2}{|c|}{ Truth } & \multicolumn{2}{|c|}{ Lie } & $\boldsymbol{F}$ & $p$ & \multicolumn{2}{|c|}{ Cohen's $d$} \\
\hline New core details in second recall & $19.19(19.67)$ & $07.68,30.71$ & $08.10(09.75)$ & $-03.81,20.01$ & 7.49 & .008 & 0.71 & $0.17,1.22$ \\
\hline New core details in reverse order recall & $09.87(10.97)$ & $05.72,14.02$ & $05.52(08.25)$ & $01.23,09.81$ & 2.99 & .089 & 0.45 & $-0.07,0.95$ \\
\hline New peripheral details in reverse order recall & $03.19(06.52)$ & $-00.27,06.66$ & $03.86(07.43)$ & $00.28,07.44$ & 0.14 & .712 & 0.09 & $-0.41,0.60$ \\
\hline Total new details in reverse order recall & $13.06(13.54)$ & $07.78,18.35$ & $09.38(10.71)$ & $03.92,14.84$ & 1.35 & .249 & 0.30 & $-0.21,0.80$ \\
\hline \multicolumn{9}{|l|}{ Model statement present } \\
\hline New core details in second recall & $62.39(57.16)$ & $50.27,74.51$ & $32.10(24.54)$ & $20.58,43.62$ & 7.24 & .009 & 0.70 & $0.16,1.22$ \\
\hline New peripheral details in second recall & $07.61(11.99)$ & $03.06,12.16$ & $16.10(17.15)$ & $11.77,20.42$ & 4.76 & .033 & 0.57 & $0.04,1.08$ \\
\hline Total new details in reverse order recall & $17.96(23.20)$ & $12.41,23.52$ & $08.42(08.34)$ & $03.14,13.70$ & 4.60 & .036 & 0.56 & $0.03,1.07$ \\
\hline
\end{tabular}


${ }^{1}$ We carried out a within-subjects ANOVA with Detail as the only factor. We examined the number of details reported in the initial recall, the number of details reported in the second recall (new and repeated details combined), and the number of details reported in the reverse order recall (new and repeated details combined). The analysis showed a significant effect, $F(2,117)=47.63, p<.001, \eta_{\mathrm{p}}{ }^{2}=.29$. Participants reported significantly fewer details in the reverse order recall $(M=47.13, S D=33.64,95 \%$ CI $[41.02,53.24])$ than in the initial recall $(M=65.60, S D=$ $37.57,95 \% \mathrm{CI}[58.77,72.42]), F(1,118)=34.86, p<.001, d=.52,95 \% \mathrm{CI}[.25, .77]$, and than in the second recall $(M=79.86, S D=51.22,95 \%$ CI $[70.56,89.15]), F(1,118)=131.53, p<.001, d=.76,95 \%$ CI $[.48,1.01]$. The interviewees also reported significantly more details in the second recall than in the initial recall, $F(1,118)=12.72, p=.001, d=.32,95 \%$ CI $[-.06, .57]$. 